\title{
Covid-19: Highest risk patients are asked to stay at home for 12 weeks
}

\section{Zosia Kmietowicz}

The BMJ

A million and a half people in England who are at very high risk of severe illness and admission to hospital because of covid-12 will receive a letter this week asking them to stay at home for at least 12 weeks.

Other people in the household will not have to remain inside but should adhere to Public Health England's advice to leave a distance of at least $2 \mathrm{~m}$ when interacting with other people.

People falling into this extremely vulnerable group include those who have undergone an organ transplantation, those having certain treatments for cancer, those with certain respiratory conditions, and pregnant women with significant heart disease (box 1). ${ }^{1}$ They have been identified through general practice records, clinical reference groups, hospital trusts, and medical royal colleges.

\footnotetext{
Box 1: Who should stay at home

Among the groups of vulnerable people the government is saying should stay at home for 12 weeks are:

- Recipients of solid organ transplants

- People with specific cancers:

- People undergoing active chemotherapy or radical radiotherapy for lung cancer

- Those with cancers of the blood or bone marrow such as leukaemia, lymphoma, or myeloma who are at any stage of treatment

- People having immunotherapy or other continuing antibody treatments for cancer

- People having other targeted cancer treatments that can affect the immune system, such as protein kinase inhibitors or PARP inhibitors

- People who have had bone marrow or stem cell transplantations in the past six months or who are still taking immunosuppression drugs

- People with severe respiratory conditions, including all those with cystic fibrosis, severe asthma, or severe chronic obstructive pulmonary disease

People with rare diseases and inborn errors of metabolism that significantly increase the risk of infections (such as severe combined immunodeficiency or homozygous sickle cell)

- People on immunosuppression therapies sufficient to significantly increase the risk of infection, and

- Pregnant women who have significant heart disease, whether congenital or acquired.
}

Robert Jenrick, secretary of state for housing, communities, and local government, who announced the new measures at a briefing on Sunday 22 March, admitted that what people were being asked to do to "will be tough" but that it was necessary to protect the NHS and to save lives.

He said that a network of local hubs would ensure that vulnerable people who did not have family, friends, or neighbours to ensure they had everything they needed would have parcels left on their doorsteps with food and medical supplies.

"This will be an especially worrying time for those with serious underlying health conditions and that is why we are urgently acting to ensure extremely vulnerable individuals are taking extra steps to shield themselves and that the essential items they need are supplied to them," said Jenrick.

England's deputy chief medical officer, Jenny Harries, said that these patients would receive care at home or in their usual clinics. She said that anyone who did not receive a letter in the next week but who thought they fell into the very high risk category should contact their GP for advice.

At the briefing the prime minister did not rule out imposing further restrictions on people's movements if they did not adhere to the social distancing advice announced last week. ${ }^{2} \mathrm{He}$ reiterated the government's preference of delaying and reducing the number of cases of covid-19 to allow the NHS to cope with voluntary measures.

"We thank the majority of people who are behaving properly, but some people are not making it easy because they are congregating, and we will have to think about that over the next 24 hours. The best thing everybody can do is observe social distancing and stay at home," said Johnson.

Over the weekend NHS staff continued to complain about the lack of personal protective equipment, with some saying on social media that they were being treated like "lambs to the slaughter."

Speaking on BBC Radio 4's Today news programme on 23 March, England's health secretary, Matt Hancock, said, "It has got better over the weekend. We have enough of it [equipment]. We got a shipment out to all the major hospitals and a new helpline, so if you are on the frontline and can't access the equipment you need you can phone in and we are using the army to distribute it. It is our responsibility to get them the equipment they need."

In terms of ventilators, Hancock said that " serious progress" had been made. He said the government had now "managed to get over 12000 ventilators after starting with 5000."

He said, "We have been buying ventilators and also dealing with companies who are turning their production over to ventilators. We also need trained staff to run them, especially an invasive ventilator." 
On 22 March the UK had 5683 confirmed cases of covid-19, and 281 people had died from the disease.

1 Public Health England. COVID-19: guidance on shielding and protecting people defined on medical grounds as extremely vulnerable. 21 Mar 2020. https://www.gov.uk/government/ publications/guidance-on-shielding-and-protecting-extremely-vulnerable-persons-fromcovid-19.

2 Mahase E. Covid-19: UK starts social distancing after new model points to 260000 potential deaths. BMJ 2020;368:m1089. 10.1136/bmj.m1089 32184205

Published by the BMJ Publishing Group Limited. For permission to use (where not already granted under a licence) please go to http://group.bmj.com/group/rights-licensing/ permissions 